\title{
Misturas de forrageiras anuais e perenes para sucessão à soja em sistemas de integração lavoura-pecuária
}

\author{
Luís Armando Zago Machado(1) \\ (1)Embrapa Agropecuária Oeste, BR 163, Km 253,6, Caixa Postal 661, CEP 79804-970 Dourados, MS. E-mail: zago@cpao.embrapa.br
}

\begin{abstract}
Resumo - O objetivo deste trabalho foi avaliar a produção de forragem de espécies perenes e de suas misturas com espécies anuais, durante a estação seca, e a produtividade de grãos de soja cultivada em sucessão. Os experimentos foram realizados em 2007 e 2008, em Dourados e em São Gabriel do Oeste, MS. Em 2007, foram avaliadas as espécies Urochloa brizantha ('Xaraés') e Megathyrsus maximus ('Tanzânia'), em cultivos solteiros ou em misturas com Eleusine coracana (capim-pé-de-galinha), Pennisetum glaucum (milheto) e Sorghum bicolor (sorgo forrageiro). Em 2008, foram avaliados $U$. decumbens e as cultivares Xaraés e Tanzânia em cultivos solteiros ou em misturas com milheto e sorgo forrageiro. As forrageiras foram avaliadas sob sucessivos cortes, durante a estação seca, e a soja no verão, no cultivo em sucessão. As misturas de espécies anuais e perenes não aumentam a produção de forragem, mas melhoram sua distribuição ao longo da estação seca. As forrageiras anuais têm maior participação na produção de forragem das misturas no início da estação seca, e as perenes no final dessa estação. A relação folha/colmo das forrageiras perenes individuais é maior do que a das misturas. Os tratamentos avaliados não têm efeito sobre a soja cultivada em sucessão.

Termos para indexação: Glycine max, Panicum, Brachiaria, estacionalidade de produção, plantas de cobertura, safrinha.

\section{Mixtures of annual and perennial forage for soybean sucession in crop-livestock integration systems}

\begin{abstract}
The objective of this work was to evaluate the forage production of perennial species and their mixtures with annual species, during the dry season, and the grain yield of soybean grown in succession. Experiments were carried out in 2007 and 2008, in Dourados and São Gabriel do Oeste, MS, Brazil. In 2007, the evaluated treatments were Urochloa brizantha ('Xaraés') and Megathyrsus maximus ('Tanzania'), single or in mixtures with Eleusine coracana (finger millet), Pennisetum glaucum (pearl millet) and Sorghum bicolor (forage sorghum). In 2008, U. decumbens and the cultivars Tanzania and Xaraés, single or in mixtures with pearl millet and forage sorghum, were evaluated. The evaluations were done in forages under successive cuts, during the dry season, and in soybean grown in succession, in the summer. Mixtures of annual and perennial species do not increase forage production, but improve its distribution throughout the dry season. The annual forages have higher participation in the forage production of mixtures at the beginning of the dry season, and the perennials at the end of that season. Leaf/stem ratio of individual perennial forages is greater than that of the mixtures. The evaluated treatments have no effect on soybean grown in succession.
\end{abstract}

Index terms: Glycine max, Panicum, Brachiaria, production seasonality, cover crops, second crop.

\section{Introdução}

Um dos principais problemas da pecuária é a estacionalidade da produção de forragem que é determinada, principalmente, pela redução da temperatura e da precipitação pluvial durante a estação seca (Costa et al., 2005). Assim, em razão da diminuição no crescimento das plantas, somente de 20 a $30 \%$ da produção anual de forragem ocorre nesse período, o que torna necessária a redução da taxa de lotação ou o aumento da disponibilidade de pasto. Caso a suplementação do rebanho com volumoso não esteja prevista, há grande redução da disponibilidade de forragem, já que em condições de pastejo a demanda de alimento é quase contínua (Barioni et al., 2003).

Este problema pode ser resolvido nos sistemas de integração lavoura-pecuária (ILP), pois é possível aumentar temporariamente a área de pastagem durante a estação seca (Machado et al., 2011). O aumento da disponibilidade de forragem nesse período pode ser feito com o cultivo de forrageiras anuais em sucessão às culturas de verão, consórcio de forrageiras e culturas para grãos, uso de cereais de duplo propósito, rotação lavoura-pastagem, produção de 
volumosos - conservados ou em capineiras - e vedação de pastagens (Fontanelli et al., 2009; Machado et al., 2011).

Em regiões tropicais, as principais forrageiras anuais semeadas no final da estação chuvosa são milheto e sorgo; entretanto, nas regiões subtropicais, destacamse a aveia-preta e aveia-branca, azevém e espécies de trevo (Fontaneli et al., 2009; Machado et al., 2011, Silva et al., 2011).

Nas últimas décadas, com o aumento da disponibilidade de sementes e a geração de conhecimentos, tornou-se possível o cultivo de forrageiras perenes dos gêneros Urochloa e Megathyrsus, para a formação de pastagens temporárias (Machado etal.,2011).As plantas destes gêneros produzem forragem em condições de baixa disponibilidade hídrica e apresentam, ainda, vantagens em relação às anuais, ao produzir forragem por um período mais longo e deixar maior quantidade de palha para o plantio direto (Portes, 2000; Mattos et al., 2005; Machado \& Assis, 2010).

O cultivo de forrageiras em rotação com culturas agrícolas é importante para produção de palha e raízes, e promove condições físicas do solo que aumentam a viabilidade do plantio direto. São relatadas melhorias na qualidade física do solo (Marchão et al., 2007), na recuperação dos teores de matéria orgânica (Wendling et al., 2005), na redução da incidência de plantas daninhas e de doenças (Braz et al., 2006; Toledo-Souza et al., 2008) e no controle de nematoides (Dias-Ariera et al., 2002; Carneiro et al., 2006).

Nos sistemas de integração lavoura-pecuária, pastagens cultivadas durante a estação seca são de extrema importância. Nesse período, o produtor pode fazer um bom planejamento da produção de forragem, normalmente escassa nessa época, e preencher uma das principais lacunas na pecuária. Além disso, em razão da melhoria nas propriedades físicas do solo, da ciclagem de nutrientes e da proteção do solo contra ação erosiva das primeiras chuvas, o cultivo na entressafra tem reflexos potencialmente benéficos à produção de grãos na safra seguinte. Para cultivo em sucessão à soja, Machado et al. (2004) e Machado \& Assis (2010) identificaram algumas forrageiras, como o sorgo forrageiro (Sorghum bicolor) 'Santa Elisa' e os capins tanzânia (Megathyrsus maximus) e xaraés (Urochloa brizantha). De acordo com os autores, essas forrageiras são as mais adequadas para compor sistemas de integração lavoura-pecuária.
Embora existam informações sobre espécies forrageiras e de cobertura do solo, anuais e perenes, em cultivos solteiros, faltam estudos sobre os efeitos da mistura dessas forrageiras no aumento da produtividade e na possível melhoria da distribuição da forragem produzida durante a estação seca. De acordo com Maia et al. (2000), a mistura de forrageiras anuais e perenes é uma prática interessante. São escassos, também, resultados a respeito do cultivo da soja em sucessão a forrageiras consorciadas.

O objetivo deste trabalho foi avaliar a produção de forragem de espécies perenes e de suas misturas com espécies anuais, durante a estação seca, e produtividade de grãos de soja cultivada em sucessão.

\section{Material e Métodos}

Os experimentos foram realizados durante os anos de 2007 e 2008, em dois locais: São Gabriel do Oeste, MS, (19²4'S, 5434" W), clima Aw, segundo a classificação de Köppen, em Latossolo Vermelho distrófico, a 662 m de altitude; e na Embrapa Agropecuária Oeste, em Dourados, MS, $\left(22^{\circ} 14^{\prime} \mathrm{S}, 5^{\circ} 49^{\prime \prime} \mathrm{W}\right)$, clima Cwa, em Latossolo Vermelho distroférrico, a $408 \mathrm{~m}$ de altitude. As precipitações pluviais ocorridas no período experimental estão apresentadas na Figura 1, e as características químicas do solo na Tabela 1.

$\mathrm{O}$ delineamento experimental utilizado foi um fatorial 9x2x2, em que o fator A são as forrageiras e suas misturas, o fator B os dois locais (São Gabriel do Oeste e Dourados) e o fator C as duas épocas de avaliação (2007 e 2008), com quatro repetições.

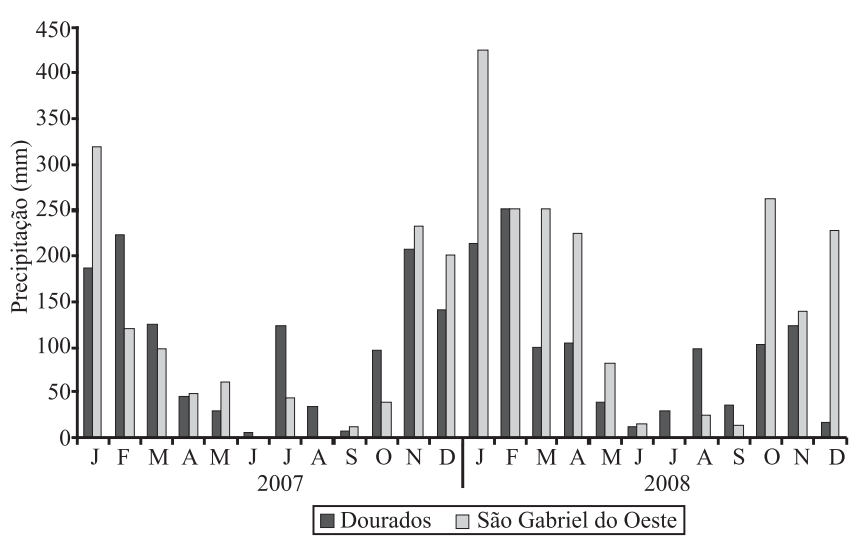

Figura 1. Precipitação mensal em Dourados e São Gabriel do Oeste, MS, no período de janeiro/2007 a dezembro/2008. 
Foram avaliados as forrageiras Urochloa decumbens (Stapf) R.D. Webster (Syn. Brachiaria decumbens), $U$. brizantha (Hochst. ex A. Rich.) R.D. Webster (Syn. B. brizantha), cultivar Xaraés, e Megathyrsus maximus (Jacq.) B.K. Simon \& S.W.L. Jacobs (Syn. Panicum maximum), cultivar Tanzânia, solteiros ou em misturas com Pennisetum glaucum (L.) R.Br. (milheto 'BRS 1501'), Sorghum bicolor L. Moench (sorgo forrageiro 'IAC Santa Elisa') e Eleusine coracana (L.) Gaertn. (capim-pé-de-galinha). Não foi possível avaliar $U$. decumbens solteiro ou em misturas com as forrageiras anuais no primeiro ano, devido à baixa emergência de plantas. Embora o lote de sementes apresentasse $78 \%$ de valor cultural, pode ter ocorrido falha humana no que se refere à análise e identificação do lote. Outro problema que pode ter ocorrido, que não constava da análise de semente, trata-se do vigor. Sementes com baixo vigor têm menor capacidade de emergência no campo, principalmente em condição de estresse. No segundo ano, o capim-pé-de-galinha não foi avaliado em misturas com as espécies perenes, por não terem sido encontradas sementes no mercado.

As parcelas de 3,6x6,0 m foram constituídas por oito linhas de cada espécie, espaçadas em $0,40 \mathrm{~m}$. As forrageiras foram semeadas em sucessão à soja, em plantio direto, com semeadora mecanizada, em 19/3/2007 e 25/3/2008, em Dourados, e em 20/3/2007 e 28/3/2008, em São Gabriel do Oeste. Como em Mato Grosso do Sul a cultura do milho safrinha é a mais comumente utilizada para a sucessão à soja, as forrageiras foram sempre semeadas após a data limite para a semeadura do milho, que é 10/3, prorrogável por mais 5 a 10 dias - data estipulada pelo Ministério da Agricultura Pecuária e Abastecimento, conforme portaria 321 de 26/11/2006 que trata do zoneamento agrícola. Foram empregadas as taxas de semeadura de sementes puras viáveis de $4 \mathrm{~kg} \mathrm{ha}^{-1}$, para 'Tanzânia' e U. decumbens, e de $5 \mathrm{~kg} \mathrm{ha}^{-1}$, para 'Xaraés'. Nas misturas, acrescentaram-se $7 \mathrm{~kg} \mathrm{ha}^{-1}$ de capim-pé-de-galinha ou milheto ou sorgo-forrageiro (Kichel \& Kichel, 2001). O valor cultural das sementes foi, em 2007, de 49,2, 78,1, 83,9, 92,2, 95, 7 e 96,5\% e, em 2008, de 30,2, 79,0,
86,4, 90,2 e 91,5\%, para 'Tanzânia', U. decumbens, 'Xaraés', milheto e sorgo forrageiro, respectivamente.

As forrageiras foram cortadas $20 \mathrm{~cm}$ acima do nível do solo, em: 15/5/2007, 18/7/2007, 28/9/2007, 4/6/2008, 28/8/2008 e 2/10/2008, em São Gabriel do Oeste, e 18/5/2007, 17/7/2007, 1/10/2007, 28/5/2008, 18/8/2008 e 29/9/2008, em Dourados. Em seguida, foram colhidas amostras de $4 \mathrm{~m}$ de comprimento nas quatro linhas centrais, espaçadas de $0,4 \mathrm{~m}\left(6,4 \mathrm{~m}^{2}\right)$, tendo-se deixado como bordadura duas linhas de cada lado e $1 \mathrm{~m}$ no início e no final da parcela. Das amostras, foram retiradas subamostras de aproximadamente $0,2 \mathrm{~kg}$, para separação das espécies anuais e perenes, e suas respectivas frações de colmo e folha. $\mathrm{O}$ restante das amostras foi devolvido às respectivas parcelas. Posteriormente, as subamostras foram secas em estufa com circulação forçada de ar a $61^{\circ} \mathrm{C}$, por 72 horas, e pesadas para determinação da matéria seca.

Para dessecação das forrageiras, foi aplicado o herbicida glifosato (360 $\mathrm{g} \mathrm{L}^{-1}$ do equivalente ácido de $\mathrm{N}$-fosfonometil glicina), em duas ocasiões: uma aos 21 dias antes da semeadura e outra no dia da semeadura, nas doses 3 e $2 \mathrm{~L} \mathrm{ha}^{-1}$ (ou de 1.080 e $720 \mathrm{~g} \mathrm{ha}^{-1}$ do equivalente ácido de $\mathrm{N}$-fosfonometil glicina), respectivamente. $\mathrm{Na}$ primeira aplicação, como adjuvante, acrescentaram-se $2 \%$ de sulfato de amônio à calda $\left(150 \mathrm{~L} \mathrm{ha}^{-1}\right) \mathrm{e}$, em Dourados, utilizouse o herbicida 2,4 D, para o controle de folhas largas.

Sobre a palha das forrageiras, foram semeadas as cultivares de soja BRSMS Piraputanga e BRS 256RR, em plantio direto mecanizado, em 15/11/2007 e 20/11/2007, em São Gabriel do Oeste e Dourados, respectivamente. Na safra 2008/2009, a soja não foi avaliada, já que não se estabeleceu em Dourados, em consequência do forte estresse hídrico e, em São Gabriel do Oeste, que fica a $385 \mathrm{~km}$ da Embrapa, ocorreram problemas com a parceria local que impossibilitaram o monitoramento de pragas e doenças. A semeadora foi regulada para distribuir $250 \mathrm{~kg} \mathrm{ha}^{-1}$ de fertilizante NPK 0-30-15 e 355.555 sementes viáveis de soja por hectare. Estas sementes, tratadas com fungicida carboxina + tiram, receberam posteriormente inoculação com Bradyrhizobium japonicum, por meio de inoculante

Tabela 1. Características químicas das áreas experimentais em São Gabriel do Oeste e em Dourados, MS.

\begin{tabular}{|c|c|c|c|c|c|c|c|c|c|c|}
\hline Local & $\mathrm{pH} \mathrm{CaCl}{ }_{2}$ & $\mathrm{Al}^{+}$ & $\mathrm{Ca}$ & $\mathrm{Mg}$ & $\begin{array}{r}\mathrm{H}^{+} \mathrm{Al}_{3} \\
-\left(\mathrm{cmol}_{\mathrm{c}}\right.\end{array}$ & $\mathrm{K}^{+}$ & $\mathrm{P}$ & CTC efetiva & $\begin{array}{c}\mathrm{V} \\
(\%)\end{array}$ & $\begin{array}{c}\mathrm{MO} \\
\left(\mathrm{g} \mathrm{kg}^{-1}\right)\end{array}$ \\
\hline São Gabriel do Oeste & 5,0 & 0,1 & 2,8 & 1,2 & 5,5 & 0,28 & 17,5 & 4,4 & 44 & 33,8 \\
\hline Dourados & 5,3 & 0,0 & 7,2 & 3,1 & 5,8 & 0,47 & 19,9 & 10,7 & 65 & 34,4 \\
\hline
\end{tabular}


turfoso. A colheita mecânica da soja foi realizada em seis linhas de $3 \mathrm{~m}$ de comprimento, espaçadas em $45 \mathrm{~cm}$, no centro da parcela, em 27/3/2008 e em 29/3/2008, em São Gabriel do Oeste e em Dourados, respectivamente.

Os resultados foram submetidos à análise de variância, tendo-se aplicado o teste $\mathrm{F}$, e as médias foram comparadas pelo teste de Tukey, a 5\% de probabilidade, com auxilio do programa Assistat 7.4 Beta.

\section{Resultados e Discussão}

Em 2007, não houve interação entre as misturas de forrageiras e locais. A produção média de forragem da mistura da cultivar Tanzânia + sorgo forrageiro foi superior às demais, seguida de 'Xaraés' + sorgo, e 'Tanzânia' + milheto ou 'Tanzânia' solteiro (Tabela 2). A produção de forragem foi maior em Dourados (4.545 $\mathrm{kg} \mathrm{ha}^{-1}$ ) do que em São Gabriel do Oeste $\left(3.370 \mathrm{~kg} \mathrm{ha}^{-1}\right)$. Com respeito à relação folha/colmo, ocorreu interação entre as misturas e os locais e, para esta variável, com os capins 'Xaraés' e 'Tanzânia' solteiros, os resultados foram inferiores em Dourados, em comparação a São Gabriel do Oeste. Para a mistura 'Tanzânia' + milheto, esta relação foi inferior em São Gabriel do Oeste, em comparação a Dourados. A relação folha/colmo foi maior nas forrageiras perenes solteiras, e variou de 4,8 a 13,7.

Em 2008, ocorreu interação entre misturas e locais de avaliação, e a cultivar Xaraés solteira foi mais produtiva, em São Gabriel do Oeste do que em Dourados (Tabela 1). O capim 'Tanzânia' solteiro e $U$. decumbens solteiro ou em consórcio com sorgo foram mais produtivos em Dourados, em relação a São Gabriel do Oeste. Em Dourados, os tratamentos foram semelhantes entre si, mas, em São Gabriel do Oeste, o capim 'Xaraés' solteiro foi mais produtivo que $U$. decumbens + sorgo. Na média dos locais, 'Xaraés' solteiro e 'Tanzânia' + milheto foram mais produtivos que $U$. decumbens + sorgo.

O sorgo apresentou comportamento diferenciado das demais espécies anuais, ao manter algum crescimento durante toda a estação seca, o que contribuiu para a produção de forragem da mistura, fato já relatado por Machado et al. (2004), quando avaliaram diversas forrageiras anuais em cultivo solteiro. Em estudo com diversas forrageiras em cultivo solteiro, Machado \& Assis (2010) identificaram os capins 'Tanzânia' e
'Xaraés' e o sorgo forrageiro como os mais produtivos, tendo superado o milheto. Embora com outra metodologia, com plantas em crescimento livre para a produção de palha, Ferreira et al. (2010) identificaram o capim 'Tanzânia' como mais produtivo que milheto em cultivos solteiros. Com o objetivo de produção de palha, Pacheco et al. (2008) observaram a superioridade de um híbrido de sorgo em relação a $U$. brizantha e destes em relação ao milheto e ao capim-pé-de-galinha, quando as plantas foram avaliadas durante toda a estação seca, em cultivo solteiro.

A eficiência do uso da água é um fator que pode ajudar a explicar este comportamento. Singh \& Singh (1995) observaram que o sorgo é superior ao milho e ao milheto, em condição moderada de umidade. Para Kanemasu et al. (1984), o sorgo é mais eficiente no uso da água do que o milheto, tanto para a produção de matéria seca como para a produção de grãos. Entre as espécies do gênero Urochloa, Mattos et al. (2005) concluíram que $U$. brizantha apresenta maior tolerância ao deficit hídrico.

No presente estudo, a mistura de espécies anuais e perenes não teve acréscimo significativo na produção de forragem. Estes resultados estão de acordo com os obtidos por Maia et al. (2000), que compararam capim 'Tanzânia' solteiro ou misturado ao milheto, em diferentes combinações de densidade de semeadura, no período de verão. Embora os autores não tenham obtido diferenças significativas, numericamente a produção das misturas foi de 24 a $62 \%$ do capim 'Tanzânia' solteiro.

Quanto à relação folha/colmo, ocorreu interação entre misturas e locais, em 2007, e os capins 'Tanzânia' e 'Xaraés' solteiros foram superiores em São Gabriel do Oeste, em comparação a Dourados. Neste local, a mistura 'Tanzânia' + milheto apresentou maior relação folha/colmo, em comparação a São Gabriel do Oeste. Em 2008, não ocorreu interação entre misturas e locais, e o capim 'Tanzânia' e suas misturas apresentaram as maiores relações folha/colmo (Tabela 2).

A menor relação folha/colmo, obtida em 2007 com as misturas de forrageiras, em comparação às espécies perenes solteiras, pode estar relacionada à maior participação das espécies anuais na mistura. Estas, por serem mais precoces, elongaram seus colmos para a emissão das inflorescências, enquanto as perenes ainda estavam no estádio vegetativo (Tabelas 2 e 3 ). Estes resultados estão de acordo com os obtidos por 
Machado \& Assis (2010), se calculada a relação folha/colmo, com base nos resultados de produção de forragem e de folhas. As maiores relações folha/colmo foram obtidas com as forrageiras perenes solteiras, ou quando a espécie anual teve pouca participação na mistura. Relações folha/colmo superiores a 5,0 foram relatadas por Rodrigues et al. (2008), para 'Xaraés', e entre 0,39 e 1,89, por Santos et al. (1999), e de 2 a 4, por Brâncio et al. (2003), para 'Tanzânia'. As relações folha/colmo relatadas pelos últimos autores foram inferiores à obtida no presente estudo, que foi de 5,6 a 13,7. Este fato pode ser explicado pelo fato que, durante o período de avaliação, o capim 'Tanzânia' não floresceu e, portanto, não emitiu colmos. Esta é uma característica fisiológica dessa cultivar, que necessita de dias curtos para indução ao florescimento (Santos et al., 1999). À medida que a relação folha/ colmo aumenta, há mais folhas disponíveis para os animais, o que contribui para o aumento da ingestão, já que estes preferem consumir a fração folhas (Forbes \& Hodgson, 1985). Além do aspecto quantitativo, as folhas apresentam melhor qualidade do que os colmos (Queiroz et al., 2000). Embora Machado et al. (2004) tenham obtido maior relação folha/colmo com o sorgo 'Santa Elisa', em comparação ao milheto, esta diferença não foi observada nas misturas dessas gramíneas com as forrageiras perenes.

A produção de forragem variou de acordo com a época e, em 2007, os capins 'Xaraés' e 'Tanzânia' solteiros apresentaram maior produção na segunda e terceira avaliações (Tabela 3). Com exceção da mistura 'Tanzânia' + pé-de-galinha, as demais tiveram sua produção reduzida a partir da primeira avaliação, principalmente em razão da diminuição do crescimento das espécies anuais que encerraram seu ciclo precocemente, exceto o sorgo forrageiro. Na primeira avaliação, 'Tanzânia' e 'Xaraés' misturados com sorgo ou milheto apresentaram maior produção de forragem. Na segunda avaliação, somente o capim 'Tanzânia' foi mais produtivo do que 'Xaraés' + milheto. $\mathrm{Na}$ terceira avaliação, os capins solteiros foram mais produtivos do que o capim 'Xaraés' em misturas com capim-pé-de-galinha ou milheto. Não foi observado efeito do local.

Em 2008, as produções de forragem obtidas na segunda avaliação foram significativamente maiores do que as da primeira e terceira avaliações, com exceção das misturas 'Xaraés' + sorgo e U. decumbens + milheto. Destaca-se a importância das forrageiras anuais como forma de antecipar o pastejo no início da estação seca.

Tabela 2. Produção de forragem e relação folha/colmo de espécies perenes, cultivadas solteiras ou em mistura com anuais, na estação seca de 2007 e 2008, em Dourados e São Gabriel do Oeste, MS $^{(1)}$.

\begin{tabular}{|c|c|c|c|c|c|c|}
\hline \multirow[t]{2}{*}{ Tratamento } & \multicolumn{2}{|c|}{ Forragem $\left(\mathrm{kg} \mathrm{ha}^{-1}\right.$ de MS) } & \multirow[t]{2}{*}{ Média } & \multicolumn{2}{|c|}{ Relação folha/colmo } & \multirow[t]{2}{*}{ Média } \\
\hline & Dourados & São G. do Oeste & & Dourados & São G. do Oeste & \\
\hline & \multicolumn{6}{|c|}{2007} \\
\hline Urochloa brizantha 'Xaraés' & 4.130 & 1.970 & $3.050 \mathrm{c}$ & $4,8 \mathrm{abcB}$ & $11,6 \mathrm{aA}$ & $8,2 \mathrm{a}$ \\
\hline Megathyrsus maximus 'Tanzânia' & 4.745 & 3.180 & $3.963 \mathrm{abc}$ & $5,6 \mathrm{abB}$ & $13,7 \mathrm{aA}$ & $9,7 \mathrm{a}$ \\
\hline U. brizantha 'Xaraés' + PG & 3.693 & 2.185 & $2.939 \mathrm{c}$ & $0,8 \mathrm{dA}$ & $1,9 \mathrm{bcA}$ & $1,4 \mathrm{bc}$ \\
\hline U. brizantha 'Xaraés' $+\mathrm{M}$ & 4.004 & 3.528 & $3.766 \mathrm{bc}$ & $0,9 \mathrm{dA}$ & $0,4 \mathrm{cA}$ & $0,6 \mathrm{c}$ \\
\hline U. brizantha 'Xaraés' $+\mathrm{S}$ & 5.557 & 3.643 & $4.600 \mathrm{ab}$ & $1,4 \mathrm{cdA}$ & $0,8 \mathrm{bcA}$ & $1,1 \mathrm{bc}$ \\
\hline M. maximus 'Tanzânia' + PG & 3.968 & 2.693 & $3.331 \mathrm{c}$ & $2,3 \mathrm{bcdA}$ & $4,5 \mathrm{bA}$ & $3,4 \mathrm{~b}$ \\
\hline M. maximus 'Tanzânia' $+\mathrm{M}$ & 5.041 & 4.737 & $4.889 \mathrm{ab}$ & $6,2 \mathrm{aA}$ & $0,6 \mathrm{cB}$ & $3,4 \mathrm{~b}$ \\
\hline \multirow[t]{2}{*}{ M. maximus 'Tanzânia' $+\mathrm{S}$} & 5.219 & 5.025 & $5.122 \mathrm{a}$ & $1,5 \mathrm{cdA}$ & $1,0 \mathrm{bcA}$ & $1,2 \mathrm{bc}$ \\
\hline & \multicolumn{6}{|c|}{2008} \\
\hline U. decumbens & $4.371 \mathrm{aA}$ & $2.231 \mathrm{bcB}$ & $3.306 \mathrm{ab}$ & $1,2 \mathrm{c}$ & $1,3 \mathrm{c}$ & $1,2 \mathrm{~d}$ \\
\hline U. brizantha 'Xaraés' & $3.588 \mathrm{aB}$ & $5.066 \mathrm{aA}$ & $4.327 \mathrm{a}$ & $5,5 \mathrm{ab}$ & $3,3 \mathrm{c}$ & $4,4 \mathrm{abc}$ \\
\hline M. maximus 'Tanzânia' & $4.752 \mathrm{aA}$ & $3.295 \mathrm{abcB}$ & $4.024 \mathrm{ab}$ & $6,9 \mathrm{a}$ & $7,6 a b$ & $7,2 \mathrm{a}$ \\
\hline U. decumbens $+\mathrm{M}$ & $3.350 \mathrm{aA}$ & $2.996 \mathrm{abcA}$ & $3.173 \mathrm{ab}$ & $1,5 \mathrm{bc}$ & $0,9 \mathrm{c}$ & $1,2 \mathrm{~d}$ \\
\hline U. decumbens $+\mathrm{S}$ & $3.726 \mathrm{aA}$ & $1.680 \mathrm{cB}$ & $2.703 b$ & $1,5 \mathrm{bc}$ & $1,9 \mathrm{c}$ & $1,7 \mathrm{~cd}$ \\
\hline U. brizantha 'Xaraés' + M & $2.669 \mathrm{aA}$ & $3.287 \mathrm{abcA}$ & $2.978 \mathrm{ab}$ & $2,4 \mathrm{bc}$ & $3,5 \mathrm{c}$ & $3,0 \mathrm{bcd}$ \\
\hline U. brizantha 'Xaraés' + S & $3.928 \mathrm{aA}$ & 4.096abA & $4.012 \mathrm{ab}$ & $4,0 \mathrm{abc}$ & $4,6 a b c$ & $4,3 \mathrm{bc}$ \\
\hline M. maximus 'Tanzânia' $+\mathrm{M}$ & $4.776 \mathrm{aA}$ & 4.996abA & $4.386 \mathrm{a}$ & $4,1 \mathrm{abc}$ & $3,5 \mathrm{c}$ & $3,8 \mathrm{bcd}$ \\
\hline M. maximus 'Tanzânia' $+\mathrm{S}$ & $3.999 \mathrm{aA}$ & $3.180 \mathrm{abcA}$ & $3.590 \mathrm{ab}$ & $3,1 \mathrm{abc}$ & $7,9 \mathrm{a}$ & $5,5 \mathrm{ab}$ \\
\hline
\end{tabular}

${ }^{(1)}$ Médias seguidas de letras iguais, minúsculas nas colunas e maiúsculas nas linhas, não diferem significativamente, pelo teste Tukey, a $5 \%$ de probabilidade. PG, capim-pé-de-galinha; M, milheto; S, sorgo forrageiro. 
As misturas 'Xaraés' + sorgo e 'Tanzânia' + milheto foram menos produtivas na terceira avaliação, em comparação à primeira e à segunda. Na primeira avaliação, a mistura de $U$. decumbens + milheto apresentou maior produção de forragem que $U$. decumbens e 'Tanzânia' solteiros ou em mistura com sorgo forrageiro. $\mathrm{Na}$ segunda avaliação, 'Xaraés' solteiro foi mais produtivo que $U$. decumbens + milheto ou sorgo, 'Xaraés' + milheto e 'Tanzânia' + milheto. A competição do milheto exercida sobre 'Tanzânia', quando cultivados em misturas, foi evidenciada por Maia et al. (2000).

A participação das espécies anuais decresceu com o avanço da estação seca e foi nula na última avaliação, com exceção do sorgo (Tabela 3). Isto ocorreu em consequência da rapidez no estabelecimento e do ciclo curto das forrageiras anuais, já relatados por Timossi et al. (2007) e por Machado \& Assis (2010). As forrageiras perenes aumentaram sua participação, com o declínio do crescimento das espécies anuais. De acordo com Portes et al. (2000), somente após 150 dias o capim 'Marandu', em mistura com milheto, apresentou acréscimo significativo em sua taxa de crescimento. No presente trabalho, a exceção foi o sorgo forrageiro 'Santa Elisa', que manteve alguma participação na produção de forragem até a terceira avaliação, quando o milheto e o capim-pé-de-galinha já haviam encerrado seu ciclo de crescimento. Este comportamento da cultivar Santa Elisa, que se destacou em relação a híbridos de sorgo e ao milheto, já havia sido descrito por Machado et al. (2004).

Embora o capim 'Tanzânia' tenha apresentado a maior produção, foram observadas manchas foliares e senescência precoce de folhas, causadas por Bipolaris maydis que, segundo Martinez-Franzener et al. (2010), podem comprometer a produção e a qualidade da forragem.

A altura das plantas e a produtividade de grãos de soja não apresentaram diferenças significativas entre os tratamentos (Tabela 4). Há estudos sobre forrageiras em sistemas de produção, em que as culturas antecessoras proporcionam mudanças no ambiente, mas não resultam em alterações na produtividade de grãos das culturas utilizadas em sucessão, em anos em que as condições meteorológicas foram normais (Carvalho et al., 2004; Muraishi et al., 2005; Machado \& Assis, 2010; Machado \& Valle, 2011). Talvez períodos mais longos de avaliação possam alterar o ambiente a ponto de influenciar significativamente a produção de grãos

Tabela 3. Produção de forragem da espécie solteira ou da mistura e participação da espécie anual, avaliadas em três épocas ${ }^{(1)}$.

\begin{tabular}{|c|c|c|c|c|c|c|}
\hline \multirow[t]{2}{*}{ Tratamento } & \multicolumn{2}{|c|}{ 1' Avaliação } & \multicolumn{2}{|c|}{ 2ª Avaliação } & \multicolumn{2}{|c|}{ 3a Avaliação } \\
\hline & $\begin{array}{c}\text { Forragem } \\
\left(\mathrm{kg} \mathrm{ha}^{-1}\right)\end{array}$ & $\begin{array}{c}\text { Espécie anual } \\
(\%)\end{array}$ & $\begin{array}{c}\text { Forragem } \\
\left(\mathrm{kg} \mathrm{ha}^{-1}\right)\end{array}$ & $\begin{array}{c}\text { Espécie anual } \\
(\%)\end{array}$ & $\begin{array}{c}\text { Forragem } \\
\left(\mathrm{kg} \mathrm{ha}^{-1}\right)\end{array}$ & $\begin{array}{c}\text { Espécie anual } \\
(\%)\end{array}$ \\
\hline & \multicolumn{6}{|c|}{2007} \\
\hline Urochloa brizantha 'Xaraés' & $245 \mathrm{cB}$ & - & $1.324 \mathrm{abA}$ & - & $1.722 \mathrm{aA}$ & - \\
\hline Megathyrsus maximus 'Tanzânia' & $642 \mathrm{bcB}$ & - & $2.040 \mathrm{aA}$ & - & $1.700 \mathrm{aA}$ & - \\
\hline U. brizantha 'Xaraés' + PG & $1.070 \mathrm{bAB}$ & 72 & $1.642 \mathrm{abA}$ & 77 & $617 \mathrm{cB}$ & 2 \\
\hline U. brizantha 'Xaraés' + M & $2.509 \mathrm{aA}$ & 85 & $974 \mathrm{bB}$ & 66 & $670 \mathrm{bcB}$ & 0 \\
\hline U. brizantha 'Xaraés' + S & $2.816 \mathrm{aA}$ & 79 & $1.236 \mathrm{abB}$ & 76 & $1.097 \mathrm{abcB}$ & 41 \\
\hline M. maximus 'Tanzânia' + PG & $1.013 \mathrm{bcA}$ & 59 & $1.625 \mathrm{abA}$ & 57 & $1.015 \mathrm{abcA}$ & 0 \\
\hline M. maximus 'Tanzânia' + M & $2.436 \mathrm{aA}$ & 73 & $1.468 \mathrm{abB}$ & 7 & $1.484 \mathrm{abB}$ & 0 \\
\hline \multirow[t]{2}{*}{ M. maximus 'Tanzânia' $+\mathrm{S}$} & $2.833 \mathrm{aA}$ & 83 & $1.563 \mathrm{abB}$ & 77 & $1.252 \mathrm{abcB}$ & 26 \\
\hline & \multicolumn{6}{|c|}{2008} \\
\hline U. decumbens & $153 \mathrm{cbB}$ & - & $2.972 \mathrm{abA}$ & - & $181 \mathrm{aB}$ & - \\
\hline U. brizantha 'Xaraés' & $533 \mathrm{abcB}$ & - & $3.425 \mathrm{aA}$ & - & $369 \mathrm{aB}$ & - \\
\hline M. maximus 'Tanzânia' & $347 \mathrm{bcB}$ & - & $3.150 \mathrm{abA}$ & - & $526 \mathrm{aB}$ & - \\
\hline U. decumbens $+\mathrm{M}$ & $1.501 \mathrm{aA}$ & 83 & $1.472 \mathrm{dA}$ & 4 & $200 \mathrm{aB}$ & 0 \\
\hline U. decumbens $+\mathrm{S}$ & $549 \mathrm{bcdB}$ & 75 & $1.916 \mathrm{cdA}$ & 24 & $238 \mathrm{aB}$ & 15 \\
\hline$U$. brizantha 'Xaraés' + M & $1.096 \mathrm{abcA}$ & 67 & $1.542 \mathrm{dA}$ & 5 & $341 \mathrm{aB}$ & 0 \\
\hline U. brizantha 'Xaraés' + S & $1.063 \mathrm{abcB}$ & 61 & $2.591 \mathrm{abcA}$ & 23 & $358 \mathrm{aC}$ & 17 \\
\hline M. maximus 'Tanzânia' + M & $1.399 \mathrm{abB}$ & 65 & $2.322 \mathrm{bcdA}$ & 5 & $659 \mathrm{aC}$ & 0 \\
\hline M. maximus 'Tanzânia' $+\mathrm{S}$ & $567 \mathrm{bcdB}$ & 57 & $2.584 \mathrm{abcA}$ & 23 & $439 \mathrm{aB}$ & 10 \\
\hline
\end{tabular}

${ }^{(1)}$ Médias seguidas de letras iguais, minúsculas nas colunas e maiúsculas nas linhas, não diferem significativamente, pelo teste Tukey, a $5 \%$ de probabilidade. PG, capim-pé-de-galinha; M, milheto; S, sorgo forrageiro. 1aㅡ 2a e 3a avaliações: maio, junho, setembro de 2007; e junho, agosto e setembro de 2008, respectivamente. Resultados médios obtidos em Dourados e São Gabriel do Oeste, MS, nas estações secas de 2007 e 2008. 
Tabela 4. Altura de plantas e produtividade de grãos de soja, cultivada em sucessão a misturas de forrageiras anuais e perenes, em Dourados e São Gabriel do Oeste, MS, na safra 2007/2008.

\begin{tabular}{|c|c|c|c|c|c|c|}
\hline \multirow[t]{2}{*}{ Tratamento } & \multicolumn{2}{|c|}{ Altura das plantas $(\mathrm{cm})$} & \multirow[t]{2}{*}{ Média } & \multicolumn{2}{|c|}{ Produtividade de grãos $\left(\mathrm{kg} \mathrm{ha}^{-1}\right)$} & \multirow[t]{2}{*}{ Média } \\
\hline & Dourados & São G. Oeste & & Dourados & São G. Oeste & \\
\hline Urochloa brizantha 'Xaraés' & 99,3 & 98,3 & 98,8 & 2.308 & 2.020 & 2.164 \\
\hline Megathyrsus maximus 'Tanzânia' & 100,5 & 101,6 & 101,0 & 2.384 & 2.309 & 2.346 \\
\hline U. brizantha 'Xaraés' + PG & 96,8 & 101,8 & 99,3 & 2.381 & 1.988 & 2.185 \\
\hline U. brizantha 'Xaraés' + M & 101,3 & 96,3 & 98,8 & 2.461 & 1.789 & 2.125 \\
\hline U. brizantha 'Xaraés' + S & 99,3 & 94,6 & 96,9 & 2.373 & 1.703 & 2.038 \\
\hline M. maximus 'Tanzânia' + PG & 101,8 & 105,0 & 103,4 & 2.188 & 2.020 & 2.104 \\
\hline M. maximus 'Tanzânia' $+\mathrm{M}$ & 97,8 & 95,0 & 96,4 & 2.404 & 1.910 & 2.157 \\
\hline M. maximus 'Tanzânia' $+\mathrm{S}$ & 96,0 & 98,7 & 97,4 & 2.189 & 2.090 & 2.140 \\
\hline
\end{tabular}

PG, capim-pé-de-galinha; M, milheto; S, sorgo forrageiro. Os resultados de rendimento de grãos foram ajustados para o teor de $13 \%$ de água.

das culturas (Machado \& Assis, 2010). No algodão, cultivado em sucessão a diversas forrageiras, Ferreira et al. (2010) observaram maior rendimento de fibra quando esta cultura foi antecedida dos capins 'Tanzânia' e 'Mombaça'.

Pelo o exposto, a mistura de forrageiras anuais e perenes pode ser uma estratégia para a formação de pastagens temporárias, com melhor distribuição da forragem produzida durante a entressafra da soja. Estes resultados contribuem para minimizar a estacionalidade da produção de forragem, conforme relatado por Barioni et al. (2003) e por Costa et al. (2005), para atender à necessidade do rebanho ao longo do ano.

Quando em misturas, as espécies anuais são mais competitivas, o que pode comprometer o desenvolvimento das perenes. Assim, é necessário que se estude as densidades de semeadura mais adequadas, principalmente para evitar a participação excessiva das forrageiras anuais. $\mathrm{O}$ uso de forrageiras anuais pode não ser uma boa estratégia no estabelecimento de pastagens permanentes, porque elas podem comprometer o desenvolvimento inicial destas, e o ganho de algumas semanas de antecipação do pastejo pode representar perdas nos anos sucessivos.

\section{Conclusões}

1. As misturas de espécies anuais e perenes não aumentam a produção de forragem, mas melhoram sua distribuição ao longo da estação seca.

2. As forrageiras anuais, misturadas às perenes, têm maior participação na produção de forragem no início da estação seca, e as perenes, no final.
3. A relação folha/colmo das forrageiras perenes é maior do que a das misturas.

4. As misturas avaliadas não têm efeito sobre o rendimento de grãos da soja, quando cultivada em sucessão.

\section{Referências}

BARIONI, L.G.; MARTHA JUNIOR, G.B.; RAMOS, A.K.B.; VELOSO, R.F.; RODRIGUES, D. de C.; VILELA, L. Planejamento e gestão do uso de recursos forrageiros na produção de bovinos em pastejo. In: SIMPÓSIO SOBRE MANEJO DA PASTAGEM, 20., 2003, Piracicaba. Anais. Piracicaba: FEALQ, 2003. p.105-154.

BRÂNCIO, P.A.; EUCLIDES, V.P.B.; NASCIMENTO JÚNIOR, D. do; FONSECA, D.M. da; ALMEIDA, R.G. de; MACEDO, M.C.M.; BARBOSA, R.A. Avaliação de três cultivares de Panicum maximum Jacq. sob pastejo: disponibilidade de forragem, altura do resíduo pós-pastejo e participação de folhas, colmos e material morto. Revista Brasileira de Zootecnia, v.32, p.55-63, 2003.

BRAZ, A.J.B.P.; PROCÓPIO, S.O.; CARGNELUTTI FILHO, A.A.; SILVEIRA, P.M.; KLIEMANN, H.J.; COBUCCI, T.; BRAZ, G.B.P. Emergência de plantas daninhas em lavouras de feijão e de trigo após o cultivo de espécies de cobertura do solo. Planta Daninha, v.24, p.621-628, 2006.

CARNEIRO, R.G.; MONACO, A.P. do A.; LIMA, A.C.C.; NAKAMURA, K.C.; MORITZ, M.P.; SCHERER, A.; SANTIAGO, D.C. Reação de gramíneas a Meloidogyne incognita, a $M$. paranaensis e a $M$. javanica. Nematologia Brasileira, v.30, p.287-291, 2006.

CARVALHO, M.A.C. de; ATHAYDE, M.L.F.; SORATTO, R.P.; ALVES, M.C.; ARF, O. Soja em sucessão a adubos verdes no sistema de plantio direto e convencional em solo de Cerrado. Pesquisa Agropecuária Brasileira, v.39, p.1141-1148, 2004.

COSTA, K.A. de P.; ROSA, B.; OLIVEIRA, I.P. de; CUSTÓDIO, D.P.; SILVA, D.C. e. Efeito da estacionalidade na produção de matéria seca e composição bromatológica da Brachiaria brizantha cv. Marandu. Ciência Animal Brasileira, v.6, p.187-193, 2005. 
DIAS-ARIERA, C.R.;FERRAZ, S.;FREITAS, L.G.; MIZOBUTSI, E.H. Penetração e desenvolvimento de Meloidogyne incognita, $M$. javanica e Heterodera glycines em quatro gramíneas forrageiras. Nematologia Brasileira, v.26, p.35-41, 2002.

FERREIRA, A.C. de B.; LAMAS, F.M.; CARVALHO, M. da C.S.; SALTON, J.C.; SUASSUNA, N.D. Produção de biomassa por cultivos de cobertura do solo e produtividade do algodoeiro em plantio direto. Pesquisa Agropecuária Brasileira, v.45, p.546-553, 2010.

FONTANELI, R.S.; SANTOS, H.P. dos; FONTANELI, R.S. (Ed.). Forrageiras para integração lavoura-pecuária-floresta na região sul-brasileira. Passo Fundo: Embrapa Trigo, 2009. 340p.

FORBES, T.D.A.; HODGSON, J. Comparative studies of the influence of sward conditions on the ingestive behavior of cows and sheep. Grass and Forage Science, v.40, p.69-77, 1985.

KANEMASU, E.T.; SINGH, P.; CHAUDHURI, U.N. Water use and water-use efficiency of pearl millet and sorghum. In: INTERNATIONAL SYMPOSIUM ON AGROMETEOROLOGY OF SORGHUM AND MILLET IN THE SEMI-ARID TROPICS, 1982, Patancheru. Proceedings. Patancheru: International Crops Research Institute for the Semi-Arid Tropics, 1984. p.175-181.

KICHEL, A.N.; KICHEL, A.G. Requisitos básicos para boa formação e persistência de pastagens. Campo Grande: Embrapa Gado de Corte, 2001. 8p. (Embrapa Gado de Corte. Gado de Corte divulga, 52).

MACHADO, L.A.Z.; ASSIS, P.G.G. de. Produção de palha e forragem por espécies anuais e perenes em sucessão à soja. Pesquisa Agropecuária Brasileira, v.45, p.415-422, 2010.

MACHADO, L.A.Z; ASSIS, P.G.G. de; PALOMBO, C. Sorgo para pastejo/corte e cobertura do solo no período de outono/ inverno (safrinha) em Mato Grosso do Sul. Dourados: Embrapa Agropecuária Oeste, 2004. 19p. (Embrapa Agropecuária Oeste. Boletim de pesquisa e desenvolvimento, 16).

MACHADO, L.A.Z.; BALBINO, L.C.; CECCON, G. Integração lavoura-pecuária-floresta. 1: Estruturação dos sistemas de integração lavoura-pecuária. Dourados: Embrapa Agropecuária Oeste, 2011. 45p. (Embrapa Agropecuária Oeste. Documentos, 110).

MACHADO, L.A.Z.; VALLE, C.B. do. Desempenho agronômico de genótipos de capim-braquiária em sucessão à soja. Pesquisa Agropecuária Brasileira, v.46, p.1454-1462, 2011.

MAIA, M.C.; PINTO, J.C.; ANDRADE, I.F. de. Estabelecimento de pastagem de capim-tanzânia usando milheto como cultura acompanhante. Revista Brasileira de Zootecnia, v.29, p.1312-1319, 2000.

MARCHÃO, R.L.; BALBINO, L.C.; SILVA, E.M. da; SANTOS JUNIOR, J. de D.G. dos; SÁ, M.A.C. de; VILELA, L.; BECQUER, T. Qualidade física de um Latossolo Vermelho sob sistemas de integração lavoura-pecuária no Cerrado. Pesquisa Agropecuária Brasileira, v.42, p.873-882, 2007.

MARTINEZ-FRANZENER, A. da S.; FRANZENER, G.; STANGARLIN, J.R. Dano causado por Bipolaris maydis em
Panicum maximum cv. Tanzânia. Semina: Ciências agrárias, v.31, p.863-870, 2010.

MATTOS, J.L.S. de; GOMIDE, J.A.; HUAMAN, C.A.M. y. Crescimento de espécies do gênero Brachiaria, sob déficit hídrico, em casa de vegetação. Revista Brasileira de Zootecnia, v.34, p.746-754, 2005.

MURAISHI, C.T; LEAL, A.J.F.; LAZARINI, E.; RODRIGUES, L.R.; GOMES JUNIOR, F.G. Manejo de espécies vegetais de cobertura de solo e produtividade do milho e da soja em semeadura direta. Acta Scientiarum. Biological Sciences, v.27, p.199-207, 2005.

PACHECO, L.P.; PIRES, F.R.; MONTEIRO, F.P.; PROCÓPIO, S. de O.; ASSIS, R.L. de; CARMO, M.L. do.; PETTER, F.A. Desempenho de plantas de cobertura em sobressemeadura na cultura da soja. Pesquisa Agropecuária Brasileira, v.43, p.815-823, 2008.

PORTES, T. de A.; CARVALHO, S.I.C. de; OLIVEIRA, I.P. de; KLUTHCOUSKI, J. Análise do crescimento de uma cultivar de braquiária em cultivo solteiro ou consorciado com cereais. Pesquisa Agropecuária Brasileira, v.35, p.1349-1358, 2000.

QUEIROZ, D.S.; GOMIDE, J.A.; MARIA, J. Avaliação da folha e do colmo de topo e base de perfilhos de três gramíneas forrageiras. 1 . Digestibilidade in vitro e composição química. Revista Brasileira de Zootecnia, v.29, p.53-60, 2000.

RODRIGUES, R.C.; MOURÃO, G.B.; BRENNECHE, K.; LUZ, P.H. de C.; HERLING, V.R. Produção de massa seca, relação folha/colmo e alguns índices de crescimento do Brachiaria brizantha cv. 'Xaraés' cultivado com a combinação de doses de nitrogênio e potássio. Revista Brasileira de Zootecnia, v.37, p.394-400, 2008.

SANTOS, P.M.; CORSI, M.; BALSALOBRE, M.A.A. Efeito da freqüência de pastejo e da época do ano sobre a produção e a qualidade em Panicum maximum cvs. Tanzânia e Mombaça. Revista Brasileira de Zootecnia, v.28, p.244-249, 1999.

SILVA, H.A. da; MORAES, A. de; CARVALHO, P.C. de F.; PONTES, L. da S. Desempenho de novilhas leiteiras em pastagens anuais de inverno sob sistema de integração lavoura-pecuária. Pesquisa Agropecuária Brasileira, v.46, p.1372-1378, 2011.

SINGH, B.R.; SINGH, D.P. Agronomic and physiological responses of sorghum, maize and pearl millet to irrigation. Field Crops Research, v.52, p.57-67, 1995.

TIMOSSI, P.C.; DURIGAN, J.C.; LEITE, G.J. Formação de palhada por braquiárias para adoção do sistema plantio direto. Bragantia, v.66, p.617-622, 2007.

TOLEDO-SOUZA, E.D. de; SILVEIRA, P.M. da; LOBO JUNIOR, M.; CAFÉ FILHO, A.C. Sistemas de cultivo, sucessões de culturas, densidade do solo e sobrevivência de patógenos de solo. Pesquisa Agropecuária Brasileira, v.43, p.971-978, 2008.

WENDLING, B.; JUCKSCH, I.; MENDONÇA, E. de SÁ; NEVES, J.C.L. Carbono orgânico e estabilidade de agregados de um Latossolo Vermelho sob diferentes manejos. Pesquisa Agropecuária Brasileira, v.40, p.487-494, 2005.

Recebido em 19 de outubro de 2011 e aprovado em 6 de fevereiro de 2012 